\title{
FUNDAMENTOS DA CONSTRUÇÃO DOS DIREITOS HUMANOS: DAS CIVILIZAÇÕES ANTIGAS AOS TEMPOS CONTEMPORÂNEOS
}

\author{
Maria José Galleno de Souza Oliveira \\ Professora Assistente do Departamento de Filosofia \\ e Teoria Geral do Direito da USP.
}

\begin{abstract}
Resumo:
Este artigo visa discutir sobre a importância dos direitos humanos descle os mais remotos tempos da antiguidade até os dias atuais. Busca-se uma reflexão sobre a condição humana, a preservação dos homens e do universo, demonstrando que há uma completude entre homem, natureza e universo. O artigo procura fixar que a defesa aos valores escollidos pelo homem para o homem, universalmente conhecidos por Direitos Humanos, são inalienáveis, irretratáveis e supraestatais, não havendo entre eles nenhuma flexibilidade, o que implica na necessidade de reavaliá-los e reafírmá-los sempre que houver uma ameaça de violação e usurpação de tais direitos.
\end{abstract}

\section{Abstract:}

This article aims to discuss the importance of human rights from ancient times to our current days. It tries to focus on a deep reflection on the human beings. as well as, their own preservation and the preservation of the universe. This deep flection will provide a perfect connection linking man, nature and the universe. It defends the values chosen by man kind to their own species. These values universally known as human rights are inalienable and irrevocable. Having no flexibility, it implies the necessity to reevaluate them.

Unitermos: Direitos Humanos; homem; universo.

"Nós buscamos significado, ajuda, companheirismo. Precisamos de algo além de lembranças e sonhos: de esperança. Talvez, se fôssemos capazes de transcender as limitações de nossa curta vida, de existir em una realidade sobrenatural, pudéssemos até suspender a passagem do tempo. E, quem sabe, se conseguissemos de alguma forma ludibriar o tempo, não poderíamos nos reunir mais una vez com aqueles que já deixaram este mundo? Que suspendemos a passagem do tempo, quando nos tornamos 
imortais como os deuses, a vida e a morte passam a coexistir, e os mortos podem então caminhar ao lado dos vivos. Para isso nós criamos o infinito e o eterno, dedicando-nos de corpo e alma à nossa fé, qualquer que ela seja. A fé consola e justifica. Inspira a todos nós: o pintor, o professor, o cientista, o padre, o advogado, o porteiro." (GLEISER, Marcelo. O fin da terra e do céu: o apocalipse na ciência e na religião)

O Pensamento Mitológico Grego e a Construção do Homem.

Na mitologia grega, ao tempo da criação, a tarefa de criar o homem, assegurar a ele e aos outros animais todas as faculdades necessárias à sua preservação e determinar as qualidades, foram atribuídas, pelos Deuses do Olimpo, aos irmãos Epimeteu e Prometeu, cabendo ao primeiro distribuir as qualidades e ao segundo verificar se a tarefa tinha sido cumprida corretamente pelo irmão.

Epimeteu distribuiu as qualidades a cada espécie de modo a assegurar a todos, apesar de suas diferenças, igualdade de condições para possibilitar a sobrevivência de cada uma das espécies e, também, evitar que elas se destruíssem mutuamente, preservando as fontes de alimentos e o equilíbrio da natureza.

Ao aproximar-se o final de sua missão, Epimeteu conscientizou-se que não havia reservado nenhuma habilidade ou qualidade para o homem, que tinha de ser superior a todos os outros animais, pois todas já haviam sido distribuídas aos outros scres mortais. Prometeu ao aperceber-se do desespero do irmão, subiu ao Olimpo com o auxilio de Minerva e subtraiu dos deuses o fogo, trazendo-o para o homem, assegurando com esse dom a superioridade deste sobre todos os outros seres mortais. $O$ fogo forneceu ao homem o meio de construir as armas, subjugar os animais, cultivar a terra para obter sua subsistência e aquecer sua morada. Prometeu deu ao homem a habilidade e a capacidade inventiva para obter sua própria subsistência.

Apesar de dotados de tal capacidade, os homens, com o passar dos tempos, foram inundados de vícios, não se contentando com o que produziam e o que thes fora partilhado, não se conciliando com outros homens e seres, vivendo em discórdia. Zeus, vendo a destruição eminente dos homens, atribuiu-lhes as qualidades que pertencia ao próprio Zeus: o dom da política com os sentimentos de justiça (Diké) e de dignidade humana (aidos), que deveria ser distribuída igualmente para todos os 
homens, evitando assim que um homem subjugasse o outro. Atribuiu-lhes também as leis e a justiça que deveriam ser observadas e obedecidas, para evitar o caos novamente. Com a consciência da importância da perpetuação e sobrevivência da humanidade, Zeus exigia o esforço constante dos homens para organizarem-se na vida em sociedade. Apesar do acréscimo de mais uma qualidade divina, alguns homens conseguiram usálas para subjugar outros homens, concretizando-se os temores de Zeus, conseqüentemente desequilibrando o cosmos, causando males a si próprio.

Na concepção religiosa, a Bíblia no Velho Testamento - Gênesis - diz que "Deus criou o homem à sua imagem e semelhança", é o máximo da criação universal. Mas o homem caiu em tentação e foi expulso do paraíso. O Novo Testamento, na figura de Jesus Cristo, retoma a idéia da salvação do homem, pois a pessoa humana tem um valor absoluto no plano espiritual, sendo que todos são filhos de Deus Pai e todos são iguais - homens, mulheres, crianças, velhos, judeus, não-judeus, romanos, fariseus.

Tanto na mitologia grega quanto na religião cristã, o homem é criador dos seus males. Cabe ao homem ser tolerante para consigo mesmo e com todos aqueles que se encontram no universo - há a exigência do respeito absoluto à pessoa humana, no esforço supremo de evitar a autodestruição.

Transportando-se do campo mitológico e religioso, o homem racional fundamentado ao conhecimento pragmático, também concluiu que há de ser tolerante e respeitar totalmente a pessoa humana.

Diante de tais fundamentações, observa-se que a pessoa humana é o centro das preocupações do universo racional, ético e filosófico da humanidade, havendo uma eterna necessidade de protegê-la.

O estudo dos direitos humanos significa a percepção humana na autopreservação, dos primórdios da criação racional da origem humana, passando pelo sopro divino e mitológico - há a compreensão da importância histórica dos seres humanos, não podendo o homem negar sua condição humana.'

\footnotetext{
I. Hannah Arendt compreende que o labor, trabalho e ação são três atividades humanas fundamentais, porque para cada uma delas corresponde una das condiçōes básicas para as quais a vida foi dada ao homein na Terra. O labor corresponde o processo biológico do corpo humano (crescimento espontâneo, metabolismo e eventual declínio - necessidades vitais produzidas e introduzidas pelo labor no processo da vida) - é a própria vida. O trabalho corresponde ao artificialismo da existência humana (não está necessariamente contido no ciclo da vida) - é a mundanidade. A ação, corresponde à pluralidade - é a condictio per quam de toda a vida política. As três atividades e suas respectivas condições, relacionam-se intimamente com as condições mais gerais da existência humana: o nascimento e a morte, a natalidade $e$ a mortalidade. A condição humana engloba mais que as condições nas quais a vida foi dada ao homem. Nas palavras da autora, "Os homens são seres condiciomados: tudo aquilo com o qual eles entram em comtato, toma-se imediatamente uma condiģão de sua existência. $O$ mundo no qual transconte a vila
} 
Na atualidade, a agenda dos direitos humanos encontra-se na governabilidade dos sistemas internacionais.

Evolução Histórica dos Direitos Humanos.

No estudo da evolução histórica dos direitos humanos, deve-se buscar nos gregos e nas antigas civilizações o fundamento para a concepção moderna dos direitos humanos.

Segundo os antigos ordenamentos jurídicos e filosóficos, houve vários sistemas de proteção aos valores dos homens desde os primórdios das civilizações.

Os gregos consagravam as leis não-escritas (nomos ágraphon) que tanto podiam designar costumes juridicamente relevantes, como as leis universais, consideradas divinas, pois por serem uniformes e observadas por todos os Estados, foram idealizadas e concretizadas pelos Deuses. Antígona, de Sófocles, utiliza a expressão não-escrita, referindo-se a um direito superior, divino. Para Aristóteles as leis divinas são "leis comuns", pois são observadas pelo consenso universal, pela razão humana.

Os romanos, com a apreensão do conhecimento grego, estende a noção de leis não-cscritas para dircitos comuns a todos os povos, denominado ius gentium, cujo fundamento de sua vigência a todos se deve à natureza e não ao divino. As Leis das doze tábuas, estabelecendo princípios e normas visando tutelar a organização social e estatal romana, concebia a tutela aos indivíduos, estabelecendo regras referentes à liberdade, à propriedade e outras proteções aos romanos.

$\mathrm{Na}$ concepção teológica, os direitos advindos da divindade são encontrados desde os antigos egípcios, mesopotâmicos e persas, bem como nas sagradas escrituras de Abraão, Isaac e Jacó, constituindo um legado aos seus descendentes.

Em todos esses escritos, sejam teológicos ou racionais, encontram-se as idéias de igualdade, liberdade e justiça que fundamentam os direitos humanos vigentes no século XXI.

Igualmente no período que compreende a história da humanidade,

activa consiste en coisas produzidas pelas atividades humanas; mas, comstamtemente, as coisas que devem sua existência exclusivamente aos homens também condicionam os seus autores humanos. Além das condições nas quais a vida é dada ao homem na Terra e, até certo ponto, a partir delas, os homens constantemente criam as suas próprias condişōes que, a despeito de sua variabilidade e sua origem humana, possuem a mesma forga condicionamte das cosisas naturais. O gue quer que toque a vida humana ou entre em duradoura relaçăo com ela, assume imediatamente o caráter de condição da existência humana" (ARENDT, 1997, p. 17). 
denominado medieval, os fundamentos do cristianismo, que pregava a igualdade dos homens com o espírito divino na figura de Jesus Cristo.

No caminhar do homem, os iluministas iniciam uma nova fase na construção dos direitos humanos.

Porém, os preceitos desenvolvidos pelas doutrinas cristãs e iluministas, não foram suficientes para que o homem controlasse o seu desejo de superar e subjugar outros homens. Na luta constante pelo poder, há a necessidade da concretização dos princípios e fundamentos da humanidade para controlar o homem e evitar a sua destruição.

O marco desses escritos encontra-se na Carta Magna de $1215,{ }^{2}$ editada para limilar e controlar o rci tirano.

Implanta-se o direito de liberdade e igualdade, a concretização real dos anseios subjetivos da natureza humana.

Ressalta-se que tais princípios, impulsionadores dos modernos direitos humanos, beneficiavam somente a determinados grupos, decorrente do status que pertenciam: nobres e prelados.

O período seguinte, caracterizado como moderno, foi marcado pelas lutas sociais entre os diversos grupos antagônicos quanto à forma de conceber os direitos referentes à humanidade liberdade, igualdade e propriedade.

A Revolução Americana (1776) e Revolução Francesa (1789) são movimento do iluminismo, quanto à ordem tradicional vigente, que se desenvolvia na Europa, baseada na idéia de que os homens são iguais e livres naturalmente, não podendo sofrer privações e restrições quanto à vida, à liberdade, à obtenção da propriedade de bens e à segurança. ${ }^{3}$ Essas idéias tornam-se princípios da humanidade,

2. A Carta Magna de 1215, outorgada pelo rei João Scm-Terra, constituindo um documento elaborado pelos barões e prelados ingleses, no qual foi convencionado entre outros, que os monarcas reconheceriam os privilégios especiais aos barōes e prelados, restringindo o poder absoluto do monarca. Apesar de o papa Inocêncio III declarar posteriormente a nulidade do documento, pois o rei João recorreu ao papa após assiná-la, alegando que assinou mediante coação e sem o devido consentimento papal, a carta foi reafirmada várias vezes pelos monarcas que os sucedeu. Algumas garantias, entre outras, previstas na Carta Magna: liberdade à Igreja da Inglaterra; liberdade a todos os homens livres da Inglaterra; limitaçōes tributárias; taxa de isenção do serviço militar; proporcionalidade entre o serviço prestado e o benefício; fixação de um foro para as ações judiciais; proporcionalidade entre o delito e a pena aplicada; previsibilidade do devido processo legal; direito de acesso a Justiça; liberdade de locomoção (direito de ir e vir dentro e fora da Inglaterra). Foram acrescidos posteriormente: Petition of Right (1628), Habeas Corpus (1679), Bill of Right (1689) e Act of Seattlemente (1701).

3. São denominados direitos de primeira geração ou direitos individuais ou direitos civis, e dizem respeito à personalidade do indivíduo. 
inseridos permanentemente na organização social e política - reafirmados na Declaração dos Direitos do Homem e do Cidadão (1789). ${ }^{4}$

Mais uma vez, os princípios reconhecidos na afirmação da humanidade, são violados pela ganância do homem em obter benefícios e vantagens sobre os outros homens.

Uma nova etapa se inicia, com o questionamento dos valores econômicos que suplantam os homens. A grande dicotomia não se deixa negar-com a pauperização crescente dos trabalhadores e a maior exploração do trabalho, indigna-se novamente o homem que se revolta e, exige o reconhecimento e a afirmação dos valores humanos referentes ao seu trabalho e vida social. São direitos humanos frutos das lutas sociais urbanas, que tinham como protagonistas a classe operária, a burguesia industrial e o Estado liberal não-intervencionista. ${ }^{5}$

Na concepção jurídico-positivista, esses direitos são reconhecidos no inicio do séc. XX, na Constituição Mexicana $(1917)^{6}$ e na Constituição de Weimar (1919). ${ }^{7}$

Na idéia de proteção da humanidade, o homem reconhece a possibilidade de sua autodestruição, por não se conectar na universalidade. Ele vê sua fragilidade perante aos elementos que compõem o universo. Necessita urgentemente ligar-se a esses clementos, pois o homem é parte do universo. Começa assim a grande caminhada do homem para preservar os elementos do universo, para que ele também seja preservado.

No século XX, após as duas grandes guerras, principalmente a Segunda

4. La Décluration des droits de l'homme e t du citoyen, foi votada na Assembléia Nacional francesa, em 1789, proclamando a liberdade e a igualdade nos direitos de todos os homens, reivindícando os seus direitos naturais e imprescritíveis (liberdade, propriedade, segurança, resistência à opressão), em vista dos quais se constitui toda a associação política legítima. São direitos anteriores à formação da sociedade, que o Estado deve reconhecer e garantir a todos os seus cidadãos.

5. São os direitos sociais, culturais e econômicos (ou de segunda geração), dizem respeito à coletividade (conhecidos como direitos coletivos). Nesses direitos, o Estado foi chamado a uma posição ativa, deixando de lado a postura absenteísta.

6. A Constituição Inexicana (1917), teve como fonte inspiradora a doutrina anarcosindicalista, que tem entre outros os seguintes ideais: garantias às liberdades individuais e políticas, reforma agrária, proteção ao trabalhado assalariado, obrigação da educação fundamental pelos poderes públicos, etc...; que foram transformados em normas constitucionais. É a primeira Constituição a atribuir aos direitos trabalhistas, a qualidade de direitos fundamentais.

7. A Constituição de Weimar (1919), foi formulada logo após a Primeira Guerra Mundial e reformulou a concepção quanto aos direitos sociais (função social da propriedade, proteção ao trabalho, à sindicalização, à previdência social, etc...). Esta constituição serviu de orientação para outros Estados, que passaram a inserir em suas constituições os direitos sociais. Explica Manucl Gonçalves Ferreira Filho que "Como as liberdades públicas, os direitos sociais sạo direitos subjetivos. Entretanto, não são meros poderes de agir - como é típico das liberdades públicas de modo geral - mas sim poderes de exigir. São direitos "de crédito"' (FERREIRA FILHO, 1999, p. 50). 
Guerra Mundial, que abalaram a percepção do homem sobre a humanidade, desenvolvese os direitos dos povos ou direitos da solidariedade, ${ }^{x}$ que são os direitos que interessam a toda humanidade, e sua efetividade depende da união e do esforço conjunto de todos os Estados, sociedades e indivíduos das mais diferentes etnias. São eles: direito à paz, lireito ao desenvolvimento c o direito da autodeterminação dos povos, direito ao meio ambiente saudável e ecologicamente equilibrado, direito à utilização do patrimônio comum da humanidade, direito de um desenvolvimento sustentável. A humanidade agrupa-se universalmente, buscando formar um conjunto de instrumentos jurídicos e de mecanismos internacionais, para a proteção de todos os povos, visando afastar o tema dos direitos humanos como assunto exclusivo da soberania dos Estados. Os direitos dos povos ou da solidariedade são também denominados de direitos da terceira geração. 9 É criada a ONU - Organização das Nações Unidas, um organismo internacional com a finalidade de dirimir pacificamente e através do arbítrio os conflitos entre os Estados, nações e povos, e assim evitar os horrores produzidos pelos conflitos bélicos que a humanidade já conhecia bem. ${ }^{10}$

8. Explica Jorge Miranda que "o movimento de afirmação ou reivindicação destes 'direitos dos povos' corresponde, por certo, a uma significativa tendência da política e do Direito Internacional dos nossos dias, ligada à deslocação de relações entre as potências, ao despertar do chamado Terceiro Mundo e ao avolumar dos seus problemas, à crescente circulação de pessoas e bens, às novas estratégias de matériasprimas e energia.

Trata-se de questões de soberania política e econômica e trata-se também da consciência assumida (por enquanto talvez só por alguns) de injustiças criadas e mantidas no interior de uma mesına Humanidade"(MIRANDA, 1998, t.4, p. 63)

9. Paulo Bonavides entende que há a quarta geração de direitos fundamentais, introduzidos na esfera da normatividade jurílica pela globalização política e correspondem à derradeira fase de institucionalização do Esıado social. São eles: o direito à democracia, o dircito à in formação e o direito ao pluralismo. Desses direitos depende a concretização da sociedade aberta do futuro, em sua maior expressão de universalidade, para qual parece convergir o mundo no plano de todas as relações de convivência. Outrossim, compreendem que os direitos de quarta geração culminaın a objetividade dos direitos da segunda e terceira gerações, sem removê-la; como também absorvem a subjetividade dos direitos individuais ou de primeira geração (BONAVIDES, 2000, p. 525).

10. O documento que propôs a criação da ONU é a Carta do Atlântico, assinada pelo presidente dos EUA Franklin D. Roosevelt e o primeiro ministro britânico Winston Churchill. Por uma questão de ironia dos homens, na Carta do Atlântico os dois chefes políticos declararam "que o objetivo comum a seus países, na guerra em curso, era o respeito pelo direito de todos os povos de escolher a sua própria forma de governo, bem como a intenção de lutar para a restauração dos direitos soberanos e de autogoverno, para todos aqueles que foram deles privados pela força" (COMPARATO, 2001, p. 217).

A fundação da ONU foi no dia 26 de junho de 1945, em São Francisco (EUA), com assinatura da Carta das Nações Unidas por 51 países.

Após a criação da ONU, os chefes políticos dos Estados-Membros que a compōe, decidem elaborar um documento jurídico declarando os direitos dos homens. No dia 10 de dezembro de 1948, em Paris, foi aprovado pela Assembléia Geral das Nações Unidas a Declarạ̦ão Universal de Direitos Humanos. 
O século XXI iniciou-se e mais uma vez a barbárie volta a rondar os direitos humanos, na forma do espectro da luta permanente de poder. Mas, ressalta-se que não há uma luta interna de homem para homem, e sim da hegemonia de uma nação sobre todas as outras. A defesa. dos direitos humanos serve de justificativa para a agressão. Algumas nações tomam para si a defesa do mundo, com um maniqueísmo sem medidas, decide o que é certo ou errado, o que são ou não são direitos humanos, que pode ou-não viver ou morrer. Diante da constatação da realidade diária, torna-se necessário repensar a construção dos direitos humanos, reafirmando-os e reconstruindoos, exigindo de todas as nações e povos o cumprimento de tais direitos. A igualdade não é mais um direito individual, deve ser vista entre os povos - igualdade entre povos de diferentes ideologias, culturas, credos, etnias. A liberdade não se trata mais em termos individuais - todos os povos são livres para exercer as suas idéias perante os demais povos e nações. Surge um novo direito humano: a tolerância - "todos os povos, nações, Estados e civilizações devem ser tolerantes entre si"

Os Fundamentos Filosóficos na Construção do Conceito dos Direitos Humanos.

Uma das missões mais difíceís do estudioso dos direitos humanos é conseguir conceituá-lo.

Tal ocorre devido ao fato que são direitos que se ligam diretamente ao homem, portanto, há necessidade de estudar alguns aspectos fundamentais da filosofia política: as relações envolvendo as pessoas e a sociedade e os direitos da pessoa humana.

Em uma visão simplista pode-se dizer que a pessoa humana compreende individualidade e personalidade, elementos distintivos de cada um. Ao dizer-se que o homem é uma pessoa, diz-se que ele é o todo, não-somente uma parte da matéria. Elc é o universo nele mesmo, um microcosmo dentro do grande universo; sua existência ć física e espiritual, conhecimento e amor. A existência do homem está na sua alma, que domina o tempo e a morte, que é a raiz da personalidade. Dizer que o homem é uma pessoa, é dizer que no fundo da sua existência ele é o todo da parte e a parte do todo. Eis o mistério da natureza humana - o valor da pessoa, sua liberdade, seus direitos, que são os elementos que the dão dignidade absoluta, vinda de uma relação direta entre o homem e o universo.

Apesar de ser um todo, o homem não é um todo fechado, ele é um todo aberto, pois ele necessita se comunicar e amar. Por isso, ele tende naturalmente à vida social e à comunicação, e o local exato para ele suprir essas necessidades é a sociedade, 
onde realiza a vida política e social. A sociedade é um todo cujas partes são as mesmas do todo, é um organismo feito de liberdades, tem seus bens e suas atividades, que se diferenciam daquelas dos indivíduos que a compõem. Mas estes bens e atividades são e devem ser de essência humana e, por conseguinte, pervertem-se caso não contribuam para o desenvolvimento e melhoria das pessoas humanas. Deve a sociedade e os homens buscar os meios para que não ocorra a perversão dos bens e atividades daquela. Para isso, aparelha-se de valores supremos, que transcendem à sociedade política e são aspirações naturais do homem material e espiritual, denominados de direitos humanos."

Para alguns os direitos humanos são próprios da natureza humana; para outros, são direitos do homem, pois somente estes podem ser capazes de serem sujeitos e tecerem suas prerrogativas, faculdades, interesses e necessidades protegidas, resguardadas e regulamentadas pelo Estado. Isto significa que somente haverá direitos humanos se houver o reconhecimento Estatal. ${ }^{12}$

Há aqueles que concebem os direitos humanos frutos de uma determinação divina, expressão de valores sobrenaturais que encarnam nos homens. Também existem os que consideram tais direitos oriundos de uma conquista social, ${ }^{1.3}$ advindos do processo permanente de luta política entre classes antagônicas.

11. MARITAIN, 1942, pp. 13-22.

12. O. Estado Moderno se caracteriza por ter positivado o direito, construindo as ordens jurídicas modernas sobre direito subjetivos que concedem a pessoa individual âmbitos legais para uma ação guiada sempre pelas suas preferências. A comunidade jurídica tem um universo sem-fronteiras no espaço social e estende-se a todas as pessoas naturais. Para Habermas, o "liberalismo, que remonta a Locke, denunciou (ao menos desde o século XIX) o perigo representado pelas maiorias tirânicas e postulou a precedência dos direitos humanos com relação à vontade do povo. Em um caso os direitos humanos deveriam a sua legitimidade ao resultado da autocompreensão ética e da autodeterminação soberana de uma coletividade política; no outro caso, eles deveriam construir limites legítimos a partir deles mesmos que vedassem à vontade soberana do povo a usurpação das esferas de liberdade subjetivas intocáveis. Contra esses unilateralismos complementares deve-se perseverar no fato de que a idéia dos direitos humanos - o direito fundamental kantiano sobre as mesmas liberdades subjetivas de ação - nem impõe simplesmente ao legislador soberano como um limite externo, nem deve ser instrumentalizada como un requisito funcional para os scus objctivos." (IIABERMAS, 2001, p. 149)

13. "A primeira geração de direitos viu-se igualınente complementada historicamente pelo legado do socialismo, vale dizer, pelas reivindicações dos desprivilegiados a um direito de participar do 'bem-estar social', entendido como os bens que os homens, através de um processo coletivo, vão acumulando no tempo. É por essa razão que os assim chamados direitos de segunda geração, previsto pelo welfare slate, são direitos de crédito do indivíduo em relação à coletividade. Tais direitos - como o direito ao trabalho, à saúde, à educação - tền coıno sujeito passivo o Estado porque, na interação entre governantes e governados, foi a coletividade que assumiu a responsabilidade de atendê-los. $\mathrm{O}$ titular desse direito, no entanto, continua sendo, como nos direitos de primeira geração, o homem na sua individualidade. Daí a complementaridade, na perspectiva ex parte populi, entre os direitos de primeira e de segunda geração, pois estes últimos buscam assegurar as condições para o pleno exercício dos primeiros, eliminado ou atenuando os impedimentos ao pleno uso das capacidades." (LAFER, 1988, p. 127) 
Na verdade, percebe-se que em todos os estudiosos há uma condução do conceito de direitos humanos de acordo com os valores subjetivos, ideológicos, políticos, sociais, culturais e religiosos, no qual cada grupo pertence, variando de acordo com a interpretação da concepção pessoal de realidade daquele que supostamente o defende.

Após uma visão limitada e simplista dos direitos humanos, pode-se entendê-los como todos os valores da natureza consagrados pelo homem, conforme suas concepções ideológica-social-política-econômica-cultural-religiosas e o desenvolvimento das habilidades e necessidades humanas, variável no espaço e no tempo. Os direitos humanos são a grande aspiração da humanidade e estamos atrasados em relação a tais aspirações, portanto, não devemos aumentar esse atraso ainda mais com as nossas desconfianças, indolências e ceticismo, pois não temos tempo a perder.

Nas palavras de Bobbio "a história, como sempre, mantém sua ambigüidade avançando em duas direções opostas: em direção à paz ou em direção à guerra, em direção à liberdade ou em direção à opressão. O caminho da paz e da liberdade certamente passa pelo reconhecimento e pela proteção dos direitos do homem, a comę̧ar pelo direito à liberdade de culto e de consciência, que foi o primeiro a ser proclamado durante as guerras religiosas que ensangüentaram a Europa durante um século, até os novos direitos (como à privacidade e à tutela da própria imagem) que vão surgindo contra novas formas de opressão e desumanização tornadas possíveis pelo vertiginoso crescimento do poder manipulador do homem sobre si mesno e sobre a natureza. Reconheço que o caminho é difícil. Mas não há alternativas"

São Paulo, abril de 2003. 


\section{Bibliografia}

ALVES, J. A. Lindgren. Os direitos humanos como tema global. São Paulo: Perspectiva; Brasília, DF; Fundação Alexandre de Gusmão, 1994.

ARENDT, Hannah. A condição hımıına. 8.ed., revisada. Rio de Janeiro: Forenise Universilária, 1997.

BONAVIDES, Paulo. Curso de direito constitucional. 10. ed., revi. e ampl. São Paulo: Malheiros, 2000.

BOBBIO, Norberto; MATTEUCCI, Nicola; PAQUINO, Gianfranco. Dicionário de política. 5. ed. Brasília: UnB; São Paulo: Imprensa Oficial do Estado, 2000.

BOBBIO, Norberto. Teoria da política: a filosofia política e as lições dos clássicos. 3. tir., Rio de Janeiro: Campus, 2000.

BULFINCH, Thomas. O livro de ouro da mitologia: (a idade da fábula): história de deuses e heróis. 15. ed. Rio de Janeiro: Ediouro, 2001.

CANOTILHO, J. J. Gomes. Direito constitucional e teoria da constituição. 5.ed. Almedina: Coimbra, 1999.

DUFOUR, Alfred. Droits de l'homme, droit naturel et histoire: droit, individu et pouvoir de l'ecole du droit naturel à l'ecole du droit historique. Paris: Presses Universitaires de France, 1991.

COMPARATO, Fábio Konder. A afirmação histórica dos direitos humanos. 2. ed., revi. e amp. São Paulo: Saraiva, 2001.

DORNELLES, João Ricardo. $O$ que são direitos humanos. 2.ed., São Paulo: Brasiliense, 1993. (Coleção primeiros passos, n. 229)

FERREIRA FILHO, Manoel Gonçalves. Direito humanos fundamentais. 3.ed. São Paulo: Saraiva, 1999.

HABERMAS, Jürgen. A costelação pós-nacional: ensaios políticos. São Paulo: Liltera mundi, 2001.

HEYMANN-DOAT, Arlette. Libertés publiques et droits de l'homme. Paris: L.G. D. J., 1997.

LAFER, Celso. A reconstrução dos direitos humanos: um diálogo com o pensamento de Hannah Arendt. São Paulo: Companhia das Letras, 1988.

MARITAIN, Jacques. Lês droits de l'homme et la loi naturelle. New York: La Maison Française Inc., 1942.

MASSINI, Carlos Ignácio. El derecho, los derechos humanos y el valor del derecho. Buenos Aires: Abeledo-Perrot, 1987.

MORAES, Alexandre de. Direitos humanos fundamentais: teoria geral, comentários aos arts. $1^{\circ}$ a $5^{\circ}$ da Constituição da República Federativa do Brasil, doutrina e jurisprudência. 3ed. São Paulo: Atlas, 2000. (Coleção temas jurídicos).

PIOVESAN, Flávia. Temas de direitos humanos. São Paulo: Max Limonad, 1998.

STHEFANIDES, Melelaos. Os deuses do olimpo. São Paulo: 2001. 